Int. J. Electrochem. Sci., 14 (2019) $387-401$

International Journal of

ELECTROCHEMICAL

SCIENCE

www.electrochemsci.org

\title{
S-containing Molybdenum Oxide Films as pH Neutral Hydrogen Evolution Electrocatalyst prepared by Electrodeposition
}

\author{
Rasa Mardosaite $\dot{e}^{*}$ Eugenijus Valatka \\ Department of Physical and Inorganic Chemistry, Kaunas University of Technology, Radvilenu str. 19, \\ LT-50254 Kaunas, Lithuania. \\ *E-mail: rasa.mardosaite@ ktu.lt
}

doi: $10.20964 / 2019.01 .37$

Received: 9 September 2018 / Accepted: 18 October 2018 / Published: 30 November 2018

\begin{abstract}
Molybdenum sulfides, molybdenum oxides, and S-containing molybdenum oxides have been shown to be promising electrocatalysts for hydrogen evolution. In this context, amorphous Mo-O-S films on a fluorine-doped tin oxide (FTO) substrate were prepared by cyclic voltammetry using two different electrodeposition baths containing different $M o$ and $S$ precursors. Although ammonium tetrathiomolybdate (ATTM) was successfully used as a source for Mo and S, this precursor was identified as having some limitations. Therefore, an alternative electrodeposition bath containing thiourea and ammonium molybdate was presented in this work. Amorphous thiourea-molybdate-based films were annealed under an inert atmosphere, and the thermal effect was subsequently evaluated by X-ray diffraction (XRD), Fourier transform infrared spectroscopy (FT-IR), scanning electron microscopy (SEM), energy dispersive X-ray spectroscopy (EDS), UV-Vis, and Raman analysis. Finally, harsh galvanostatic electrolysis conditions were applied to perform a preliminary evaluation of the catalytic behaviour of the Mo-O-S films in a phosphate buffer solution ( $\mathrm{pH}$ 7). The Mo-O-S films prepared from the thiourea-molybdate bath showed promising stability and activity results, with a Tafel slope of $85 \mathrm{mV} \cdot \mathrm{dec}^{-1}$ in the range of overpotentials lower than $100 \mathrm{mV}$ even after prolonged HER operation. These findings open an alternative approach to the possible mechanism of Mo-O-S formation.
\end{abstract}

Keywords: molybdenum oxide; molybdenum sulfide; thiourea; electrodeposition; hydrogen evolution reaction

\section{$\underline{\text { FULL TEXT }}$}

(C) 2019 The Authors. Published by ESG (www.electrochemsci.org). This article is an open access article distributed under the terms and conditions of the Creative Commons Attribution license (http://creativecommons.org/licenses/by/4.0/). 